\title{
Lessons From The Mongolia's Millennium Development Goal-9, and Its Achievement, Opportunities $^{1}$
}

\author{
0. K hatanbold (M ongolia)
}

\section{Rationale}

7 he paper contains the outputs, conclusions and recommendations of the "Support to Achieving the MDG-9, Phase II" Project (2009-2011). It

1 has shown that reflect two interrelated activities aimed at contributing to a better quality of Mongolia's democratic governance and describes the process of detailed account of the Project activities that have resulted in the first ever set of institutionalized and fully nationally owned democratic governance indicators in support of human rights, democratic governance and zero tolerance to corruption.

The MDG-9 Project believes that the experiences shared the benefit a wide range of audiences, including international organizations and other countries that are interested in developing governance indicators and institutionalizing monitoring mechanisms. It also will be of use to the Mongolian public - both government and civil society for awareness-raising and policy action.

Those mentioned descriptions and optional explanations have been categorized on the substantial narrative reports of the project implementation and background of extended activities in the last period of 2009-2011.

\section{Brief introduction}

Although democracy has advanced rapidly in great parts of the world over the last thirty years, many countries are struggling to consolidate their sovereignty, its democratic achievements, and making democracy itself an irreversible process.

In particular, Mongolia has been paying attention towards to ensure democratic governance prinicples being declared in the National Constitution approved in 1992. Remarkable progress was achieved in the past to ensure democracy values such as human rights, freedom, fairness, transparency, equality, state of art of legacy and improvement of government system. There were 6 Parliamentary (1992, 1996, 2000, 2004, 2008, 2012), and 5 Presidential Elections (1993, 1997, 
2001, 2005, 2009) held since 1990, and number of political parties, NGOs, citizens movements, free mass media organizations established during the transition period are currently operative. Mongolia joined more than 30 human rights treaties and conventions.

Mongolia has passed number of laws though its enforcement needs comprehensive improvement. And as a consequence the governance reform process slows down. Accountability of government organizations and transparency are becoming the most challenging issues in Mongolia. Increasing of bureaucracy, cases of unauthorized fund spending, insufficient transparency, weak law enforcement, conflict of interests are the main causes of corruptions increase.

At the international level Mongolia also attracts attention of international democracy communities. The Fifth International Conference of New or Restored Democracies (ICRND-5) was held in Mongolia in 2003 and as follow up Mongolia was committed to share the experience and knowledge on its democracy achievements with the countries being facing transitions and political difficulties. Substantial progress was made in democracy development in Mongolia for past 16 years however issues such as weak citizen's trust to the government, poverty (36 percent of population live below poverty line), jobless, other socio-economic limitations, low accessibility of juridical administration service are still remain challenging.

Mongolia hosted the Fifth International Conference of New and Restored Democracies $^{2}$ (ICNRD-5) in September 2003, themed "Democracy, Good Governance and Civil Society." In accord with the recommendation of the $5^{\text {th }}$ International Conference of New and Restored Democracies held in the fall of 2003 in Ulaanbaatar, a follow up project to implement the decisions of the 5th International Conference on New and Restored Democracies has been implemented with the support of the Government of Mongolia and the UN Development Programme. Within the framework of this project, activities have been carried out in the following three directions: "Democratic Governance Indicators: Assessing the State of Mongolia's Governance" (final report), the "Country Information Note", and the "National Plan of Action to Consolidate Democracy in Mongolia".

Since improving the quality of democracy has become a political demand in both new or restored and mature democracies, there is a growing need to assess the progress in democratization and the quality of democracy. It has become evident that there is a need to develop in-country assessment tools to monitor democratic and social development progresses over time. The ICNRD-5 followup projects described in the following were implemented to create a baseline assessment, an ongoing monitoring-mechanism and offer policy guidance to 
realize its Millennium Development Goals. To date, Mongolia is the only country to have carried out such efforts in the context of ICNRD.

The World Summit convened by the United Nations in September 2000 adopted the Millennium Declaration that set forth Millennium Development Goals (MDGs) aimed at "respecting the most vulnerable and creating an environment conducive to human development." The MDGs as a common set of goals are to be achieved globally by 2015. As many other countries which endorsed the Millennium Declaration, Mongolia has defined its national MDGs and targets that reflect the country's needs and priorities. On April 21, 2005 Mongolia adopted its $9^{\text {th }}$ MDG on human rights, democratic governance, and anti-corruption. MDG-9 has three associated objectives: (1) Fully respect and uphold the Universal Declaration of Human Rights, ensure the freedom of media, and provide the public with free access to information, (2) Mainstream democratic principles and practices into life, and (3) Develop a zero-tolerance environment to corruption in all spheres of society. Mongolia remains the only country in the world to have formulated a MDG related to governance. By adopting MDG-9, Mongolia underlined the importance of democratic governance for socio-economic development and a successful achievement of other MDGs ${ }^{5}$. MDG-9 also serves to complement other MDGs by introducing an overarching goal on human rights and democracy.

The Government of Mongolia and other national stakeholders are now in the process of refining targets for MDGs 1-9, developing indicators, and establishing a national MDGs monitoring and evaluation mechanism. With the support of the United Nations Democracy Fund (UNDEF) and the UNDP, Mongolia implemented a project to support the achievement of MDG-9. The project was aimed at assisting the Government of Mongolia in implementing its commitment to foster democratic governance and strengthen human rights as reflected in MDG-9 through the institutionalization of governance measurement systems and facilitation of dialogue on governance issues.

The objective of the project was to streamline the previously developed DGIs into a manageable set of indicators for national stakeholders in order to (1) monitor the progress of democratic governance reforms and (2) build the capacities of the government, national statistical office and civil society to collect, maintain, and analyze governance related data. In addition, it assisted in the development of an inclusive and consultative framework for the systematic assessment, monitoring, and reporting of MDG-9 related goals and targets as expressed in national development plans. 


\section{Picture of the social, economic and political context}

Mongolia's exercise to develop DGIs found its logical continuation in a project to develop indicators for MDG-9 for the latter's reporting mechanism. The Project was institutionally located at the Institute of Philosophy, Sociology and Law, the locus of the previous DGIs research team. The objective of the Project was to refine previously developed DGIs to enable national stakeholders to better monitor performance in democratic governance reforms and build the capacities of the government, the national statistical office and civil society in collection, maintenance and analysis of governance related data. It was also to assist in developing an inclusive and consultative framework for the systematic assessment and monitoring of MDG-9 related goals and targets expressed in national development plans.

Mongolia hosted the ICNRD-5 in 2003, which led to a development of an ICNRD-5 project with support of UNDP. This project initiated a series of activities, including the development of DGIs, which greatly contributing to the further assessment of the government and the public service delivery. The extensive public debate and advocacy work in the following years were important milestones for a future formulation of nationally owned MDG 9 indicators.

The study and results based on the ICNRD-5 follow up projects, notably the Democratic governance assessments will be mainstreamed into the targets of MDG-9. The MDG-9 project presents a golden opportunity to institutionalize the DGIs and ensure a sustainable democracy monitoring system over time. The national research team, building upon its work with the Democratic governance indicators, is researching appropriate goal, targets, and indicators for MDG-9.

\section{Mongolia's MDG-9 achievements and opportunities}

The most important achievement of the Project was the approval of a resolution on MDGs including indicators for MDG-9 by the Parliament in January 2008. Another important step was the testing of MDG-9 survey questions by the NSO in December 2007 in a periodic household survey in compliance with an institutional contract between the Project and the NSO signed in May 2006.

The Parliament of Mongolia approved Resolution no.25 in April 2005, endorsing national MDGs and adopting the Mongolia's Ninth MDG on Human rights and Democratic governance and anti-corruption. The Mongolian case, a having governance related $\mathrm{MDG}$, is unique and novel experience among international MDGs development efforts. The Parliament Resolution no.13 approved in January 2008 made more focused and refined amendments to the previous resolution, including 12 specific indicators for MDG 9. MDGs based 
NDS of Mongolia adopted in April 2008 was a strong indication of state support and ownership towards achieving MDGs.

Mongolia being considered the MDG 9 as the pre-requisite of success of all eight MDGs achievement in 2015 has formulated and approved the MDG 9 as additional through Parliament Resolution in 2005. While Mongolia was developing interventions to achieve MDG 9 it was recognized that it isn't separable part of MDGs based National Development Strategy (NDS). Regarding the MDG 9 against the other MDGs there were no ready available approaches and guidelines to monitor, estimate costs thus the demand to adequately define target indicators, develop and introduce monitoring mechanisms to observe MDG 9 implementation ${ }^{6}$ appears to be high.

Following objectives were aimed to achieve within the Mongolia's democracy and democratic governance to support in achieving MDG 9:

- Strengthen capacity of government, NGOs and stakeholders in MDGs implementation and its monitoring;

- Attract citizens attention to the democratic governance related issues;

- Use democratic governance indicators in relation to MDG 9

- Establish democratic dialogue among the stakeholders

Following risks were regarded as relevant in project implementation to achieving MDG 9:

- Postpone due to the change in the government structure, political situation;

- Limited access of poor, vulnerable groups to obtain information, quality and reliability of information delivered to the public is low;

-Ability to be accountable is low for government organizations employees, insufficient time, skills;

- Likeness to complete institutionalization process of DGIs to the end of the project is low due to the budget constraints.

Following activities have been planned to undertake to address these issues:

- Organize seminars, meetings, international forums at each level and build lobby;

- Strengthen capacity and advocate related government organizations and other cooperating agencies;

- Develop and implement strategy for poor and vulnerable groups;

- Incorporate MDG 9 monitoring, reporting process and MDG 9 needs assessment;

- Seek for donor's additional support and assistance.

Accomplishment of MDG 9 will have direct impact on achievement of all MDGs thus all population of Mongolia, mainly poor and vulnerable groups will benefit from this project. It is expected that transparency and accountability 
of central and local governmental organizations will be improved as a result of undertaken activities to provide support to improve relationship between government and citizens and extensively carry out advocacy.

Inter realtions between "Support in achieveing MDG 9" Project goals, planned outputs, implemented activities and achieved resutls were well linked. Following objectives were aimed to achieve:

- Strengthen capacity of government, non-government organizations and stakeholders in MDG 9 implementation and its monitoring

- Attract citizens attention to the democratic governance related issues

- Use democratic governance indicators in relation to MDG 9

- Establish democratic dialogue among the stakeholders

Accordingly, project outputs have been designed more in broad and with substantial workload. MDG 9 implementation has set indicators in the statistical yearbook of the National Statistical Office (NSO). Further there are some minor issues to be addressed for the rest of the project period nevertheless the project results in overall were successful.

As a result of project implementation it can be said that number of important steps towards to achieve MDG 9 in 2015 have been undertaken. It includes:

- Improvement and approval human rights and democratic governance indicators by Parliament of Mongolia (POM), organizations identified with the commitments to improve the methodology, monitor and assess performance by each indicator, build and maintain database, all these were the $1^{\text {st }}$ step undertaken towards to build institutionalization.

- NGOs network was established to ensure Civil Society Organizations (CSOs) participation in the monitoring and assessment of MDG 9.

- Government, NSO and National Human Rights Committee (HRNC) are cooperating in producing baseline data for democratic governance implementation indicators

- Undertaking advocacy, training, seminars, study international experiences, conducting extensive discussions were steps done towards to raise public awareness and build capacity of related stakeholders in implementing human rights and democratic governance (HRDG).

- Allowing Non-Government Oranizations (NGOs), including NGOs representing women and vulnerable groups, to participate in nationwide discussions has provided opportunity for women and citizens of vulnerable groups to equally access information.

- Some tests have been done to analyze government interventions.

As far as Mongolia hosting the international conference concerned ICNRD-5 Follow-Up Project was developed and implemented under the UNDP support to turn the conference decisions and recommendations into actions. Number of 
activities has been implemented within the project towards to define Democratic Governance Indicators ${ }^{7}$ (DGIs), prepare country information sheet, develop national action program and estimate citizens' social index. It was defined 117 main and 14 supplementary indicators on 4 general issues on democratic governance assessment within the project.

This effort to assess the quality, depth, and breadth of the democratic experience drew on multiple sources of information and data in an attempt to triangulate the democratic assessment and provide an inclusive process for democratic discussion and reform. Both qualitative and quantitative methods were used to gather and analyze the data within the IDEA framework. The national surveys in 2005, 2008, 2010 in eight Mongolian aimags were conducted, eliciting the views of 1200 citizens on various aspects of democracy. In addition, 50 focus group meetings and dialogues were conducted, making an effort to target marginalized groups, such as the herders, rural/urban poor, migrants and low-skilled workers. A sample of members of the parliament was also surveyed with the same questionnaire in order to compare public perception with that of the legislators.

The Democratic governance indicators public opinion survey showed popular attitudes toward the democratic transition, the development of democracy in the country, the main problems that Mongolia's democracy needed to confront. Results revealed that general support for democracy is higher than levels of support for the actual process of democracy in Mongolia. This result is further differentiated across the urban rural divide, where rural dwellers are generally more satisfied with democracy than their urban counterparts. In addition, support for democracy and the democratic process are higher among those in the higher income strata.

Approval of MDG 9 to ensure human rights and develop democratic governance in addition to eight MDGs in 2005 became new for international practice. Democratic governance is the strong tool, important pre-requisite to ensure economic growth and achieve MDGs.

Expected outputs are improved policy reform and legal environment, established institutionalised DGIs and formal mechanizms for MDG 9 monitoring and reporting, public awareness and knowledge on MDG 9 increased and participation of vulnerable groups in public debates increased.

Within the framework of activities, outputs, outcomes specified in the project document the effectiveness, sustainability and relevance, efficiency and impacts will be attempt to assess the links between the goals, objectives and activities proposed by the project, achieved outcomes, encountered problems and difficulties, unforeseen conditions, lessons learned, new experiences gained and provide proposal for its further improvement. 
The following findings ${ }^{8}$ have been shown the implementation of MDG-9 process:

1. Implementation of MDG 9 to ensure human rights and develop democratic governance among the other MDGs is recognized as a new practice for the MD. This is new and challenging issue and was come up in relation of goal to "build humanitarian democratic society with market orientation" as specified in the Constitution of the country.

2. In order to provide assistance in project activities towards to strengthen human rights and democratic governance in Mongolia the UNDP approached often in a flexible manner considering national peculiarities and changing circumstances and this required to input substantial efforts as well as time from UNDP.

3. Since MDG 9 is a new issue and in conditions of having lack of experience, professional staff, institutional capacity the outcomes reflected in the project document were defined in broad. In terms of time factor and sources of capacity, the project was designed to be of extensive outreach and workload.

4. 117 main, 14 supporting indicators to measure performance on democracy and democratic governance were improved down to 12 indicators (1 was removed) by Parliament Resolution no. 13, organizations were identified to be committed to improve methodology, monitor and assess performance by each indicators, build and maintain database and these were the $1^{\text {st }}$ step undertaken towards to build institutionalization. Further, the time will show how good and rational the MDG-9 12 indicators have been developed, how well they could express governance democracy.

5. The CSOs network to participate in the monitoring and assessment of MDG 9 implementation established during project period became the project important success. The group comprising of representatives of CSOs was established and the NGO "Center for democracy education" has been assigned as the leading body.

6. The network covers in total 20 NGOs and only 2 or 3 of them became capable to carry out training, advocacy and in some extend study and surveys. This limitation or non-ability to undertake effective advocacy to influence government, public shows their non-readiness to participate in monitoring and assessment of MDG 9 implementation, in providing relevant and reliable information as well. It suggests that capacity building of the network staff is to be urged.

7. Reflection of fund sources required for database building on human rights and democratic governance indicators in the state and local budgets becomes urgent issue. Substantial work was done to develop 
the module of inclusion of 3 indicators as addition to the Household Social-Economic Survey (HSES), field test, obtain international expertise, improve, and print forms in collaboration with Institute of Philosophy, Sociology and Law by the National Statistic Office, the responsible body for its data producing. It was planned to obtain information through Household Social-Economic Survey (HSES) in March, June, September and December 2008, however due to the financial constraints it wasn't done in September. The NSO made efforts to allocate funds required for obtaining this information in the future in the Midterm Fiscal Framework for 2010, meantime this issue remains uncertain for other related organizations.

8. Methodology to consolidate data on MDG 9 implementation indicators, mechanisms and institutions able to advocate government are not yet formed completely. In order to ensure sustainability of the project outputs, achieve the outcomes at desirable level the indicators are needed to be consolidated and meantime the institutions are to be built to ensure central, local governments, civil society participation and strong civil society network to be established to advocate the government and public.

9. Following difficulties are encountered while the data for MDG 9 indicators being consolidated:

- Though data for three MDG 9 indicators are collected through Household Social-Economic Survey (HSES) conducted by the NSO the methodology for data aggregation not yet defined.

- IAAC wills to hire local consultant to develop methodology to define a corruption index under the World Bank (WB) financial support however a professional expert on this field appears not available. Thus demand for professionals in field of MDG 9, in particular on corruption area, and to strengthen institutional capacity is high.

- National Human Rights Commission has planned to undertake assessment within the all conventions related to the human rights Mongolia has joined however due to the financial and human resource constraints this assessment was done on only for few conventions on Human Rights of Integrity by contracted professional experts (project financed) thus only limited assessment on human rights was undertaken.

10. Government, public knowledge and capacity on human rights and democratic governance are low. MDG 9 advocacy delivered through the website is limited, since is not accessible or limited for vulnerable groups, for those with low education, unemployed and poor. 
11. Institutionalization of $\mathrm{MDG} 9$ implementation, development of monitoring, assessment and reporting mechanisms are required to be continued even the project ends, and it is important to ensure sustainable continuity of achieved outputs and incomes.

12. It is not easy to assess the outcome of activities on human rights and democratic governance being implemented within the project for passed short period. This is relatively long term issue. However it can be said that some steps have been taken towards the outcomes began to seen. It is evidenced from the fact that government and civil society both have got well sensation on needs to undertake complex activities to measure, assess human rights and democratic governance, and advocate influencing the government and number of sustainable activities undertaken. "Outcomes" are the final results thus how MDG 9 and other goals are implemented needed to be studied, assessed, analyzed and action plans developed accordingly.

13. Participation of CSOs representing women and disable citizens in several meetings organized with 44 NGOs through CSOs network during the project implementation made substantial input to achieve the task to equally deliver information to vulnerable groups and women.

\section{In the framework conclusions ${ }^{9}$ of the MDG 9 project accomplishments are:}

1. To conclude in overall, this project made significant contribution to achieve the goals approved by the government to implement human rights and democratic governance in 2015 and the MDG 9 became the pre-requisite for achievement of the rest eight MDGs as well as good practice for sharing with other countries.

2. However there are number of urging further issues. Activities on human rights and democratic governance in Mongolia are sourced from the democratic revolution of 1990s thus is relatively new and the experience gained is not extensive. Therefore continuation of the project will raise next stage issues such as to ensure sustainable operation of institutions responsible for development of the methodology, data collection and consolidation on DGIs, undertaking monitoring and assessment, based on its results to carry out advocacy to influence government.

3. Defining and approval of indicators became legal basis for assessment of democratic governance implementation. Legalization of MDG 9 indicators provides guideline for further improvement of policy and legal framework on ensuring human rights and democratic governance further strengthening. However to ensure sustainable continuation of 
project results the legal environment is not the only important factor but the formation of financial, institutional and capacity environments as well.

4. Project has made number of specific steps towards to achieve MDG 9 in 2015 nevertheless to ensure sustainable continuation of the process it will require external and internal support for some extend. In particular it is important to foster government's ownership attitude on democratic governance issues through paying more attention on rationally creating institutional environment and ensuring its sustainability.

5. Institute of Philosophy, Sociology and Law (IPSL) was selected as the implementing agency. Especially when professional organizations and experts were lacking the selection of research organization with previous experience in human rights and democratic governance was recognized as the right decision. The IPSL is relatively experienced organization in this field and has capacity to participate in continuing activities as to undertake study, draw conclusions and recommendations, monitoring and assessing. In these areas the IPSL has a complete access to the network of related stakeholders. However it is recognized that suggestions and recommendations developed by research organizations for time being may have lack of mechanisms to impact for policy level.

6. "Inclusion of MDG 9 implementation indicators in the statistical yearbook produced by the NSO was specified as one of the measurement indicators for outcomes in the project document and this activity was going slowly. Data collection will be completed in December and time required for aggregation of data for some indicators whiles for others the methodology of aggregation is at its only development stage. Therefore inclusion of MDG 9 related indicators in the Statistical Yearbook 2009 appears not achievable.

7. It is needed to improve relationship of all activities related to the MDG 9 implementation. For instance, between MDG 9 sub-committee and Anticorruption sub-committee; organizations committed to define MDG 9 indicators; MDG 9 and other 8 MDGs; similar projects implemented

8. Paying special attention on cooperation with CSOs representing women and vulnerable groups the close cooperation was established with the "CSOs network to support MDG 9 comprising of about 20 NGOs. This was important beginning to advocate MDG 9 and empower public.

9. The model for cooperation between government, non-government and research organizations within the MDG 9 was established and partnership model - to some extent. 
10. Compiling data on MDG 9 indicators is the new activity and some difficulties encountered. Household Social-Economic Survey (HSES) conducted by the NSO originally was designed to study the poverty while DGIs are touching corruption issues. Combining these two issues in one HSES and collecting information on income and same time on corruption may have weak logic and according to the household budget survey experts, it could miss lead the household income and expenditure survey. Therefore these two areas of the study are seems not appropriate to be combined.

11. IAAC has low experience and capacity and this may have impact on raising problems in the process of collecting and consolidating the data on corruption issues of MDG 9.

12. There is a need to continue the project for period of full cycle completion if not in complex then in by segmented areas. In the absence of continuation of the project each organization responsible for particular MDG 9 indicators needs to pay attention to ensure sustainability of the activities, not to reverse from the achieved level and strengthen even more already established partnership relations.

13. Considering that National Human Rights Commission faces financial and human constraints to undertake study in human rights related conventions it is needed to address improvement of methodology and financial issues.

14. Based on above mentioned the following assessments provided to measure project outputs.

\section{In the framework of Recommendations ${ }^{10}$ of the MDG 9 project achievements and future opportunities are:}

1. Allocate funds required for expenditures of related organizaitons committed to improve DGIs, its methodology, monitor and assess implementations specified in the Parliament Resolution no.13 in the state budget.

2. Based on defined government interventions related to the MDG 9 targets to influence on policy and programs, to make consistent with government interventions included in the MDG Needs Assessment Report produced by GOM in 2007.

3. Within the institutional framework to address issues to develop mechanisms to increase demand of policy makers in MDG 9 related suggestions, conclusions and recommendations produced by research organizations. 
4. If see from the results of activities undertaken to strengthen capacity within the project it is apparent that re-building capacity will be required due to the many replacement have taken place in political positions in post election period. Therefore to address this issue it is suggested to develop and conduct training modules on regular occurrence schedule.

5. Raise awareness in human rights and democratic governance implementation among the all NGOs; improve participatory approach, experience and capacity of directly related NGOs; provide information, training, advocacy, encourage active participation to ensure sustainability of the CSOs network established to participate in the monitoring and assessment process of the democratic governance implementation.

6. Pay attention on leading participation of NGOs in assessment process of democratic governance implementation and adequate participation of related other organizations assigned by Parliament Resolution No. 13 considering their given directives, commitments and capacity. Even more the capable NGO may produce "shadow report" on MDGs in form of case studies. It is advisable to include in this report more new ideas and experiences rather critisizing the issue.

7. To undertake advocacy on human rights and democratic governance implementation via mass media as TV, radio, newspaper more extensively, to develop website more on broad issues for MDG 9 advocacy rather simply project introduction.

\section{End Notes}

1 Prepared by Khatanbold Oidov (MA), State Policy Analysis InstituteNGO, Institute of Philosophy, Sociology and Law under Mongolian Academy of Sciences. UB, 2013

${ }^{2}$ The International Conference of New or Restored Democracies (ICNRD) is an intergovernmental process open to all UN member States. Since the first Conference was held with the participation of 13 countries, the ICNRD has grown into a global event bringing together more than 100 countries from all over the world. To date, a total of six International Conferences of New or Restored Democracies were held in Manila, the Philippines (1988); Managua, Nicaragua (1994); Bucharest, Romania (1997); Cotonou, Benin (2000), Ulaanbaatar, Mongolia (2003), and the latest in Doha, Qatar (2006).

${ }^{3}$ ICRND-5 Follow-up project, UNDP Mongolia. Democratic Governance Indicators: Assessing the State of Governance of Mongolia. UB., Mongolia. 2006. pp. 55-65. 
${ }^{4}$ Ibid., pp. 67-79.

5 "Empirical research to date has found a positive and significant relationship between good governance and economic performance", note the authors of "Preliminary Survey on Donor Use of Governance Assessments" - in Governance Assessments and the Paris Declaration: Opportunities for Inclusive Participation and Ownership", UNDP OGC and Chr. Michelsen Institute, Bergen Seminar Series, Bergen, Norway, 23-25 September 2007, p.1. See also Governance for the Millennium Development Goals: Core Issues and Good Practices. United Nations, New York, January 2007

${ }^{6}$ Implementation of MDG 9 to ensure human rights and develop democratic governance among the other MDGs is recognized as a new practice for the Millennium Declaration (MD) and results of the project executed by the UNDP were recognized as case of good practice in Mongolia as well as in other countries. This is a new and challenging issue and was come up in relation of goal to "build humanitarian democratic society with market orientation" as was specified in the Constitution of the country.

7 ICNRD-5 project. Democratic Governance Indicators: Assessing the State of governance in Mongolia 2005-2006. UB, Mongolia., 2006; MDG 9 Project. Millennium Development Goal-9 indicators and the State of Democracy in Mongolia 2007-2008. UB, Mongolia., 2008;

MDG 9 Project. Changes in the State of Democratic governance in Mongolia 2009-2010. UB, Mongolia., 2010;

8 Support in Achieving MDG 9 on Human Rights and Democratic Governance in Mongolia. UB, Mongolia., 2009. pp 21-25.

${ }^{9}$ MDG 9 Project. Project Policy brief. UB, Mongolia., 2011.

${ }^{10}$ MDG 9 Project. Project Policy brief. UB, Mongolia., 2011. 